\title{
ADIÇÃO DE TORTA DE MAMONA EM SUBSTRATOS NA ACLIMATAÇÃO DE MUDAS MICROPROPAGADAS DE BANANEIRA ${ }^{1}$
}

\author{
ADRIANA NOVAIS MARTINS², EDUARDO SUGUINO ${ }^{3}$, \\ NAÍSSA MARIA SILVESTRE DIAS ${ }^{4}$, MARCOS JOSÉ PERDONÁ ${ }^{5}$
}

RESUMO-A utilização de mudas micropropagadas de bananeira que oferecem qualidade genética e fitossanitária, favorecendo o desenvolvimento, instalação e uniformidade do pomar, é importante para a exploração comercial da bananicultura. O objetivo deste trabalho foi avaliar a influência da adição da torta de mamona nos substratos na aclimatação de mudas micropropagadas de bananeira da cv. Willians. O delineamento estatístico utilizado foi o inteiramente casualizado, com 10 tratamentos, sendo 2 substratos e 5 dosagens de torta de mamona $\left(0 ; 6 ; 12 ; 18\right.$ e $\left.24 \mathrm{~g} \mathrm{vaso}^{-1}\right)$. O substrato Vivatto Slim Plus ${ }^{\circledR}$ possibilitou o melhor desenvolvimento das plantas na aclimatação. Não são recomendadas doses superiores a $12 \mathrm{~g} \mathrm{planta}^{-1}$ de torta de mamona misturadas ao substrato na aclimatação de mudas de bananeira.

Termos para indexação: Musa sp., micropropagação, banana.

\section{EFFECT OF THE ADDITION OF CASTOR BEAN PIE IN SUBSTRATES IN THE ACCLIMATIZATION OF MICROPROPAGATED BANANA PLANTLETS}

ABSTRACT: The use of micropropagated banana tree seedlings offer genetic and phytosanitary qualities, favoring the development, installation and uniformity of the yield and it is very important for the commercial exploration of banana fruits. The objective of this study was to evaluate the influence of castor oil plant pie added to the substrate in the acclimatization of micropropagated banana plantlets cv. 'Willians'. It was used a completely randomized design, with 10 treatments, being 2 substrates and 5 dosages of castor oil plant pie $\left(0 ; 6 ; 12 ; 18\right.$ and $24 \mathrm{~g}$ for each recipient). The substrate Vivatto Slim Plus ${ }^{\circledR}$ showed the best development of the plants in the acclimatization processes. Dosages above $12 \mathrm{~g}$ of castor oil plant pie for each plant mixed to the substrate are not recommended in the acclimatization of banana tree seedlings.

Index terms: Musa sp., micropropagation, banana.

\section{INTRODUÇÃO}

A instalação de um bananal comercial a partir de mudas de boa qualidade é fundamental para altas produtividades, longevidade e lucratividade do empreendimento (FURLANETO et al., 2007). As mudas micropropagadas de bananeira necessitam de um período de aclimatização em viveiros, onde permanecem em recipientes com substratos até atingirem o porte ideal para o transplantio no campo (NOMURA et al., 2009).

Vários tipos de substratos podem ser utilizados no processo de aclimatização das mudas, desde que apresentem características físicas, químicas e biológicas que proporcionem o rápido crescimento vegetativo (YAMANISHI et al., 2004).
De acordo com Silva et al. (2001), substratos compostos por palha ou casca de arroz carbonizadas, casca curtida de eucalipto ou pínus, vermiculita, areia e turfa são indicados para a aclimatização de mudas. Atualmente, substratos comerciais, acrescidos de fontes de nutrientes minerais ou orgânicas, são amplamente utilizados.

A torta de mamona é um resíduo produzido durante o processo de extração de óleo das sementes da planta. Estima-se que cada tonelada de semente de mamona processada produza cerca de $530 \mathrm{~kg}$ de torta de mamona (SEVERINO et al., 2005). Este subproduto da produção de biodiesel de mamona apresenta relação C/N de 11:1 (KIEHL, 1985), com elevado teor de nitrogênio, podendo ser utilizado como fonte de nutrientes quando misturado ao substrato.

\footnotetext{
'(Trabalho 049-10). Recebido em: 10-02-2010. Aceito para publicação em: 12-08-2010.

${ }^{2}$ Pesquisadora Científica, Dra., APTA Médio Paranapanema, Rodovia SP 333 (Assis-Marília) km 397, 19.802-970, Assis, São Paulo. E.mail: adrianamartins@apta.sp.gov.br

${ }^{3}$ Pesquisador Científico, Dr., APTA Centro Leste, Ribeirão Preto-SP. E.mal: esuguino@apta.sp.gov.br

${ }^{4}$ Programa de Pós Gradução, ESALQ/USP, Piracicaba-SP. E.mail: naissasilvestre@hotmail.com

${ }^{5}$ Pesquisador Científico, APTA Centro Leste, Ribeirão Preto-SP. E.mail: marcosperdona@apta.sp.gov.br
} 
Solos que recebem torta de mamona apresentam atividade microbiana maior quando comparados com solos que recebem esterco bovino ou bagaço de cana. A mineralização da torta de mamona ocorre de forma intensa, sendo que seus nutrientes são rapidamente liberados e disponibilizados para as plantas (SEVERINO et al., 2004).

Apesar da ampla utilização da torta de mamona, tanto nos plantios a campo como na produção de mudas de diversas espécies vegetais, as informações disponíveis na literatura especializada são escassas, sendo relatadas as suas propriedades nematicidas/inseticidas (DAMASCENO et al., 2006; RITZINGER; FANCELLI, 2006; LINS et al., 2008), sua utilização na produção de mudas de tomate (GOUZALEZ et al., 2006) e atuando como adubação orgânica na cultura da mamoneira (COSTA et al., 2008; NASCIMENTO et al., 2008; LIMA et al., 2008b).

Este estudo teve como objetivo avaliar o efeito de diferentes dosagens de torta de mamona em combinação com dois substratos comerciais na aclimatização de mudas micropropagadas de bananeira, cv. Willians.

\section{MATERIAL E MÉTODOS}

O experimento foi realizado no viveiro de produção de mudas da Usina de Reciclagem e Compostagem de Lixo "José Santilli Sobrinho", da Prefeitura Municipal de Assis, Estado de São Paulo (latitude $22^{\circ} 39^{\prime} 42^{\prime}$ ' S, longitude $50^{\circ} 24^{\prime} 44^{\prime \prime} \mathrm{W}$, altitude $546 \mathrm{~m}$ ), durante o período de abril a julho de 2008. O clima desta região é caracterizado como sendo do tipo Cfa, segundo a classificação de Köeppen, ou seja, moderadamente úmido, sem estação seca, com a precipitação do mês mais seco maior que $30 \mathrm{~mm}$, temperatura média do mês mais frio inferior a $18^{\circ} \mathrm{C}$, mas acima de $-3^{\circ} \mathrm{C}$, e a temperatura média do mês mais quente superior a $22^{\circ} \mathrm{C}$. O solo é do tipo Latossolo Vermelho distrófico.

As mudas foram micropropagadas a partir de ápices caulinares, estabelecidos em meio MS (MURASHIGE; SKOOG, 1962), modificado com a metade da concentração dos macronutrientes, acrescido de $30 \mathrm{~g} \mathrm{~L}^{-1}$ de sacarose, $1 \mathrm{mg} \mathrm{L}^{-1}$ de BAP ( 6 benzilaminopurina), solidificado com 1,6 $\mathrm{g} \mathrm{L}^{-1} \mathrm{de}$ gelan Phytagel ${ }^{\mathrm{TM}}$ e pH 5,8 ajustado antes da autoclavagem. Após a inoculação, os ápices caulinares permaneceram em sala de crescimento sob temperatura de $25 \pm 2{ }^{\circ} \mathrm{C}$ em câmara escura por 10 dias, em seguida foram submetidos ao fotoperíodo de 16 horas de claro e intensidade luminosa de $50 \mu \mathrm{mol} \mathrm{m}^{-2} \mathrm{~s}^{-1}$ por mais 20 dias. Foram realizados 6 subcultivos, com intervalos de 4 semanas. $\mathrm{O}$ enraizamento foi reali- zado em meio MS líquido modificado com a metade da concentração dos macronutrientes, acrescido de $30 \mathrm{~g} \mathrm{~L}^{-1}$ de sacarose, sem adição de hormônios e $\mathrm{pH}$ 5,8 , em frascos de $250 \mathrm{~mL}$, por 30 dias.

Após esse período, as mudas foram retiradas dos frascos, individualizadas, lavadas em água corrente para a remoção de resíduos de meio de cultura aderidos às raízes, e colocadas em bandejas com 72 células, medindo $3,5 \times 3,5 \times 6,0 \mathrm{~cm}$. O substrato utilizado nas bandejas foi o Plantmax ${ }^{\mathrm{TM}}$, sendo que as mudas permaneceram por 30 dias em estufa com $70 \%$ de sombreamento e irrigadas por nebulização por 5 minutos, acionada 5 vezes ao dia. Após este período, as mudas foram retiradas das bandejas e transplantadas em vasos de polipropileno, com capacidade de 6 litros, efetivando a instalação do experimento.

Foram utilizados 2 substratos comerciais: Vivatto Slim Plus ${ }^{\circledR}$ e Plantmax ${ }^{\mathrm{TM}}$. A torta de mamona foi adicionada nas seguintes dosagens: $0 ; 6 ; 12 ; 18$ e $24 \mathrm{~g} \mathrm{vaso}^{-1}$ que equivale a $0 ; 1 ; 2 ; 3 \mathrm{e} 4 \mathrm{t} \mathrm{ha}^{-1}$. As misturas foram homogeneizadas, e as mudas, transplantadas para os vasos. Os resultados das análises químicas dos substratos encontram-se na Tabela 1. A composição química da torta de mamona utilizada foi de 7,16\% de nitrogênio, $2,98 \%$ de fósforo, $1,12 \%$ de potássio, $0,81 \%$ de cálcio e $0,49 \%$ de magnésio.

As mudas foram mantidas em estufa coberta com filme de polipropileno transparente $(150 \mu \mathrm{m}) \mathrm{e}$ sombrite ( $50 \%$ de interceptação luminosa), por um período de 90 dias. O sistema de irrigação utilizado foi por aspersão superior, instalado a aproximadamente $1,7 \mathrm{~m}$ de altura. Durante os primeiros 30 dias, foram realizadas duas irrigações diárias de 20 minutos, com intervalos de 6 horas, de $1,7 \mathrm{~mm}\left(\mathrm{~L} \mathrm{~m}^{-2}\right)$ cada. Dos 30 aos 90 dias, as mudas passaram a receber apenas uma irrigação diária (20 minutos), com uma lâmina de aproximadamente $1,2 \mathrm{~mm}$ de água $\left(\mathrm{L} \mathrm{m}^{-2}\right)$.

O delineamento estatístico utilizado foi o inteiramente casualizado, com 10 tratamentos (fatorial $2 \times 5$ ). Cada tratamento foi representado por 8 repetições (vasos), totalizando 80 parcelas (vasos). Cada parcela foi constituída por uma muda micropropagada de bananeira da cv. Willians (subgrupo Cavendish).

Aos 90 dias após o transplantio, os vasos foram desfeitos, sendo avaliados: a altura das plantas, por meio de medições da região compreendida entre o colo da planta e a inserção da última folha, o diâmetro do colo, através da medição do colo das plantas a $1,0 \mathrm{~cm}$ do substrato, com auxílio de paquímetro, o número de folhas vivas, a massa seca do sistema radicular e da parte aérea, utilizando-se de todas as plantas de cada tratamento, sendo que os materiais 
foram separados e secos em estufa a $65^{\circ} \mathrm{C}$, por 72 horas, até peso constante.

A determinação da área foliar foi calculada adaptando-se a metodologia descrita e utilizada por Basanta et al. (2000), retirando-se 10 amostras (círculos) foliares por planta de cada tratamento $(\mathbf{n}=\mathbf{1 0})$, com raio (r) de $1,20 \mathrm{~cm}$, com auxílio de um vasador manual. Os círculos foram colocados em estufa a $65^{\circ} \mathrm{C}$ (72 horas) até peso constante, obtendo-se, assim, a correspondente massa de matéria seca (ms, g). Logo, com a área e a massa de matéria seca, foi obtida a área foliar específica por planta (repetição) $\left(\mathbf{A F e}, \mathrm{cm}^{2} \mathrm{~g}^{-1}\right)$, através das fórmulas:

$$
\text { 1) } A F e=\frac{n \cdot \pi \cdot r^{2}}{m s}
$$

Com os resultados obtidos de $\mathbf{A F e}$, obteve-se a área foliar total $\left(\mathbf{A F T}, \mathrm{cm}^{2}\right)$ de cada planta (repetição) através da equação:

$$
\text { 2) } A F T=\frac{M S F \cdot A F e}{m s}
$$

em que: MSF é a massa da matéria seca das folhas de cada repetição $(\mathrm{g}) ; \mathbf{A F e}$ é a área foliar específica por planta $\left(\mathrm{cm}^{2}\right)$, e ms é a massa da matéria seca dos círculos foliares amostrados por repetição (g).

As avaliações finais foram realizadas no laboratório da Agência Paulista de Tecnologia dos Agronegócios - APTA, Médio Paranapanema, em Assis-SP. Os resultados obtidos nas avaliações de todos os parâmetros foram submetidos à análise de variância, utilizando-se do software estatístico SAS System for Windows V8 (Statistical Analyses System, 2002), sendo que as médias foram ajustadas através de regressão polinomial para as doses de torta de mamona, ao nível de significância de 5\%.

\section{RESULTADOS E DISCUSSÃO}

Observa-se que, de modo geral, os teores de nutrientes encontrados no substrato Vivatto Slim Plus ${ }^{\circledR}$ são superiores aos do Plantmax ${ }^{\mathrm{TM}}$, principalmente em relação ao teor de matéria orgânica, significando maior teor de nitrogênio (Tabela 1).

De acordo com os resultados obtidos na análise de variância (Tabela 2), os dois substratos testados exerceram grande influência sobre as variáveis avaliadas, o mesmo ocorrendo com as doses de torta de mamona, que apresentaram diferenças significativas pelo teste $\mathrm{F}(\mathrm{P}<0,01)$ para todas as variáveis. Lima et al. (2008a) também encontraram diferenças significativas, com efeito linear das doses de torta de mamona, em variáveis de crescimento de plantas de mamona cultivadas em vaso.
As variáveis altura, diâmetro de colo e número de folhas das mudas de bananeira apresentaram comportamentos quadráticos em função das doses de torta de mamona (Figuras 1; 2 e 3). Nas três variáveis, observa-se que a dose de $12 \mathrm{~g}$ de torta de mamona por planta foi a que proporcionou o melhor desenvolvimento das plantas. Lins et al. (2008) não encontraram efeitos deletérios da torta de mamona, nas mesmas doses utilizadas neste trabalho, no desenvolvimento inicial da bananeira cv. Terra, em avaliações das mesmas variáveis. De acordo com Severino et al. (2004), a torta de mamona é um material orgânico de rápida decomposição; assim sendo, a liberação dos nutrientes para as plantas ocorre de maneira praticamente imediata, refletindo no rápido crescimento das mesmas.

Entretanto, há vários trabalhos que evidenciam os efeitos deletérios de altas doses de torta de mamona utilizada como matéria orgânica. Lima et al. (2008a) evidenciaram que doses acima de $4 \%$ de torta de mamona provocaram fitotoxidade à plantas de mamoneira cv. BRS 149 Nordestina, afetando negativamente o crescimento das plantas. Resultados semelhantes foram obtidos por Severino et al. (2004), também com a cultura da mamoneira.

Na maioria das variáveis, foram identificados resultados superiores nas plantas cultivadas no substrato Vivatto Slim Plus ${ }^{\circledR}$ quando comparado com o Plantmax ${ }^{\mathrm{TM}}$ (Tabela 3). Em relação à altura das plantas, esta diferença não foi observada na maior dose de torta de mamona (24 $\left.\mathrm{g} \mathrm{planta}^{-1}\right)$, evidenciando o caráter fitotóxico das doses mais elevadas.

A variável número de folhas mostrou diferença significativa entre os substratos somente na dose de $12 \mathrm{~g}_{\text {planta }}{ }^{-1}$. De acordo com Moreira (1987), o N juntamente com o K são os nutrientes mais importantes para a emissão e manutenção das folhas na bananeira. Estas observações levam-nos a crer que as doses inferiores a $12 \mathrm{~g}$ de torta de mamona por planta não são suficientes para suprir o teor necessário destes nutrientes para o crescimento da planta, e doses acima deste valor possam provocar fitotoxidade nestas.

As demais variáveis avaliadas, massa seca da parte aérea (MSPA), massa seca do sistema radicular (MSR) e área foliar total (AFT)- apresentaram o mesmo comportamento das outras variáveis de crescimento, sendo que as doses de torta de mamona também apresentaram efeito quadrático nestas variáveis (Figuras 4; 5 e 6 )

A MSPA (Tabela 4) apresentou-se com diferenças estatísticas entre os substratos, com exceção da dose de torta de mamona mais eleva- 
da, concordando com os resultados de altura das plantas (Tabela 3). O substrato Vivatto Slim Plus ${ }^{\circledR}$ novamente apresentou melhores resultados quando comparado com o Plantmax ${ }^{\mathrm{TM}}$. Nomura et al. (2009) encontraram resultados excelentes na aclimatação de mudas de bananeira cv. Prata-Anã quando foi utilizado substrato da mesma linha do Vivatto Slim Plus ${ }^{\circledR}$ (linha de substratos Vivatto da Technes Agrícola). Em trabalhos realizados por Lopes et al. (1996) e Silva et al. (2001), o substrato Plantmax ${ }^{\mathrm{TM}}$ demonstrou melhor desempenho no desenvolvimento de mudas de maracujazeiro-azedo (Passiflora edulis Sim. F. flavicarpa DEG) quando comparado à Vermiculita, devido principalmente ao teor de $\mathrm{N}$ mais elevado do substrato Plantmax ${ }^{\mathrm{TM}}$.
A massa seca do sistema radicular (MSR) apresentou comportamento diferenciado entre os substratos (Figura 5 e Tabela 4). De acordo com Beugnon e Champion (1966), plantas com maior diâmetro de colo tendem a ter sistema radicular mais desenvolvido, favorecendo a sobrevivência a campo e a rapidez no desenvolvimento inicial das plantas.

Os resultados obtidos nas avaliações da área foliar total (AFT) foram concordantes com o número de folhas, uma vez que a dose de $12 \mathrm{~g} \mathrm{planta}^{-1}$ apresentou os maiores valores.

TABELA 1 - Teores de nutrientes resultantes das análises químicas dos substratos Vivatto Slim Plus® e Plantmax ${ }^{\mathrm{TM}}$, utilizados no experimento. Assis-SP.

\begin{tabular}{|c|c|c|c|c|c|c|c|c|c|c|c|}
\hline \multirow{2}{*}{ Substratos } & \multirow{2}{*}{$\begin{array}{c}\mathrm{pH} \\
\mathrm{H}_{2} \mathrm{O}\end{array}$} & $\mathrm{P}$ & $\mathrm{K}$ & $\mathrm{Ca}$ & $\mathrm{Mg}$ & $\mathrm{Al}$ & $\mathrm{Al}+\mathrm{H}$ & SB & $\mathrm{B}$ & $\mathrm{Zn}$ & \multirow{2}{*}{$\frac{\mathrm{MO}}{\mathrm{g} / \mathrm{dm}^{3}}$} \\
\hline & & \multicolumn{2}{|c|}{$\mathrm{mg} / \mathrm{dm}^{3}$} & \multicolumn{5}{|c|}{$\mathrm{cmol} / \mathrm{dm}^{3}$} & \multicolumn{2}{|c|}{$\mathrm{mg} / \mathrm{dm}^{3}$} & \\
\hline Vivatto Slim Plus ${ }^{\circledR}$ & 6,0 & 126 & 450 & 6,07 & 2,08 & 0,05 & 1,22 & 8,06 & 0,48 & 1,77 & 43,8 \\
\hline Plantmax ${ }^{\mathrm{TM}}$ & 5,8 & 97 & 386 & 5,31 & 1,64 & 0,05 & 1,49 & 7,36 & 0,41 & 1,58 & 31,6 \\
\hline
\end{tabular}

Análise realizadas pela Fundação Shunji Nishimura de Tecnologia, Pompéia-SP. Metodologia utilizada para análise de $\mathrm{P}, \mathrm{K}, \mathrm{Ca}$ e Mg - Resina; Zn - DTPA-TEA; B - água quente.

TABELA 2 - Resumo da análise de variância da altura, diâmetro do colo, número de folhas, massa seca da parte aérea (MSPA) e do sistema radicular (MSR), e área foliar (AF) em função de substratos (Plantmax ${ }^{\mathrm{TM}}$ e Vivatto Slim Plus ${ }^{\circledR}$ ) e doses de torta de mamona na aclimatação de mudas micropropagadas de bananeiras, cv. Willians. Assis-SP.

\begin{tabular}{cccccccc}
\hline F. V. & GL & $\begin{array}{c}\text { Altura } \\
(\mathrm{cm})\end{array}$ & $\begin{array}{c}\text { Diâm. Colo } \\
(\mathrm{cm})\end{array}$ & $\mathrm{N}^{\mathrm{o}}$ Folhas & $\begin{array}{c}\text { MSPA } \\
(\mathrm{g})\end{array}$ & $\begin{array}{c}\text { MSR } \\
(\mathrm{g})\end{array}$ & $\begin{array}{c}\mathrm{AF} \\
\left(\mathrm{cm}^{2}\right)\end{array}$ \\
\hline Tratamentos & 9 & $655,65^{* *}$ & $6,07 * *$ & $25,26^{* *}$ & $675,54^{* *}$ & $116,29 * *$ & $4367025,28^{* *}$ \\
Substratos & $(1)$ & $152,08^{* *}$ & $1,27^{* *}$ & $2,11^{*}$ & $71,44^{* *}$ & $8,39 * *$ & $111796,10^{* *}$ \\
Doses & $(4)$ & $1425,03^{* *}$ & $13,22^{* *}$ & $56,23^{* *}$ & $1493,04 * *$ & $258,37^{* *}$ & $9784148,10^{* *}$ \\
Substratos x Doses & $(4)$ & $12,17^{* *}$ & $0,11^{* *}$ & $0,08^{\text {n.s. }}$ & $9,07 * *$ & $1,18^{*}$ & $13709,75^{*}$ \\
Resíduo & 70 & 0,57 & 0,004 & 0,39 & 0,43 & 0,24 & 2849,82 \\
\hline CV $(\%)$ & & 2,77 & 2,73 & 9,83 & 4,09 & 7,58 & 3,71 \\
\hline
\end{tabular}

** Significativo a $1 \%$ de probabilidade, pelo Teste F; * significativo a 5\% de probabilidade, pelo Teste F; ${ }^{\text {n.s. }}$ Não significativo. 
TABELA 3 - Altura das mudas $(\mathrm{cm})$, diâmetro do colo $(\mathrm{cm})$ e número de folhas de mudas micropropagadas de bananeira cv. Willians, em função de substratos e doses de torta de mamona, aos 90 dias de aclimatação. Assis-SP.

\begin{tabular}{|c|c|c|c|c|}
\hline \multirow{2}{*}{$\begin{array}{c}\text { Doses } \\
\left(\text { g.planta }{ }^{-1}\right)\end{array}$} & \multicolumn{2}{|c|}{ Substratos } & \multirow{2}{*}{ Média } & \multirow{2}{*}{ CV $(\%)$} \\
\hline & Plantmax & Vivatto & & \\
\hline \multicolumn{5}{|c|}{ Altura das mudas (cm) } \\
\hline 0 & $18,8 \mathrm{~d} B$ & $22,4 \mathrm{~d} A$ & 20,6 & 2,3 \\
\hline 6 & 27,6 c B & $31,6 \mathrm{c} \mathrm{A}$ & 29,6 & 3,3 \\
\hline 12 & 35,6 a B & 39,8 a $\mathrm{A}$ & 37,7 & 2,7 \\
\hline 18 & 32,9 b B & $34,9 \mathrm{~b} \mathrm{~A}$ & 33,9 & 1,0 \\
\hline 24 & 14,8 e $\mathrm{A}$ & 14,9 e $\mathrm{A}$ & 14,9 & 4,8 \\
\hline Média & 25,9 & 28,7 & & \\
\hline CV $(\%)$ & 3,3 & 2,3 & & \\
\hline \multicolumn{5}{|c|}{ Diâmetro do colo $(\mathrm{cm})$} \\
\hline 0 & $1,55 \mathrm{~d} B$ & $1,63 \mathrm{~d} A$ & 1,60 & 3,8 \\
\hline 6 & $2,63 \mathrm{~b} \mathrm{~B}$ & $2,82 \mathrm{~b} \mathrm{~A}$ & 2,72 & 2,6 \\
\hline 12 & 3,39 a B & 3,78 a $\mathrm{A}$ & 3,58 & 2,1 \\
\hline 18 & $2,19 \mathrm{c} \mathrm{B}$ & $2,67 \mathrm{c} \mathrm{A}$ & 2,43 & 2,2 \\
\hline 24 & 1,24 e B & 1,38 e $\mathrm{A}$ & 1,31 & 4,1 \\
\hline Média & 2,20 & 2,45 & & \\
\hline CV $(\%)$ & 3,1 & 2,4 & & \\
\hline \multicolumn{5}{|c|}{ Número de folhas } \\
\hline 0 & $5,3 \mathrm{c} \mathrm{A}$ & $5,6 \mathrm{c} \mathrm{A}$ & 5,4 & 11,4 \\
\hline 6 & $6,0 \mathrm{c} \mathrm{A}$ & $6,3 \mathrm{c} \mathrm{A}$ & 6,1 & 13,4 \\
\hline 12 & 8,8 a B & 9,3 a $\mathrm{A}$ & 9,0 & 5,1 \\
\hline 18 & $7,1 \mathrm{~b} \mathrm{~A}$ & $7,5 \mathrm{~b} \mathrm{~A}$ & 7,3 & 9,6 \\
\hline 24 & $4,0 \mathrm{~d} \mathrm{~A}$ & $4,1 \mathrm{~d} \mathrm{~A}$ & 4,1 & 11,1 \\
\hline Média & 6,2 & 6,6 & & \\
\hline CV $(\%)$ & 10,8 & 8,8 & & \\
\hline
\end{tabular}

Médias seguidas pela mesma letra maiúscula na linha e da mesma letra minúscula na coluna não diferem estatisticamente entre si, pelo teste de Tukey, a $5 \%$ de probabilidade. 
TABELA 4 - Massa seca da parte aérea (MSPA, g), massa seca do sistema radicular (MSR, g) e área foliar $\left(\mathrm{AF}, \mathrm{cm}^{2}\right)$ de mudas micropropagadas de bananeira cv. Willians, em função de substratos e doses de torta de mamona, aos 90 dias de aclimatação. Assis-SP. 2009.

\begin{tabular}{|c|c|c|c|c|}
\hline \multirow{2}{*}{ Doses (g.planta $\left.{ }^{-1}\right)$} & \multicolumn{2}{|c|}{ Substratos } & \multirow{2}{*}{ Média } & \multirow{2}{*}{$\mathrm{CV}(\%)$} \\
\hline & Plantmax & Vivatto & & \\
\hline \multicolumn{5}{|c|}{ Massa seca da parte aérea - MSPA (g) } \\
\hline 0 & 6,94 d B & $8,34 \mathrm{~d} A$ & 7,64 & 3,4 \\
\hline 6 & 14,93 с B & $17,75 \mathrm{c} \mathrm{A}$ & 16,34 & 3,8 \\
\hline 12 & 25,71 a B & 29,68 a $\mathrm{A}$ & 27,69 & 2,7 \\
\hline 18 & $22,75 \mathrm{~b} \mathrm{~B}$ & $23,89 \mathrm{~b} \mathrm{~A}$ & 23,31 & 3,2 \\
\hline 24 & 5,30 e $\mathrm{A}$ & 5,44 e $\mathrm{A}$ & 5,37 & 14,8 \\
\hline Média & 15,13 & 17,02 & & \\
\hline $\mathrm{CV}(\%)$ & 3,9 & 4,2 & & \\
\hline \multicolumn{5}{|c|}{ Massa seca das raízes (g) } \\
\hline 0 & $2,53 \mathrm{~d} A$ & $2,80 \mathrm{~d} A$ & 2,66 & 13,9 \\
\hline 6 & 6,60 с B & 7,14 c A & 6,87 & 7,2 \\
\hline 12 & 10,85 a B & 12,33 a A & 11,59 & 5,9 \\
\hline 18 & 8,59 b B & 9,44 b A & 9,01 & 5,7 \\
\hline 24 & $2,26 \mathrm{~d} A$ & $2,36 \mathrm{~d} A$ & 2,31 & 12,4 \\
\hline Média & 6,17 & 6,81 & & \\
\hline CV $(\%)$ & 8,3 & 6,9 & & \\
\hline \multicolumn{5}{|c|}{ Área foliar $\left(\mathrm{cm}^{2}\right)$} \\
\hline 0 & $829,6 \mathrm{~d}$ B & $897,4 \mathrm{~d} A$ & 863,5 & 2,9 \\
\hline 6 & 1465,5 c A & $1502,6 \mathrm{c} \mathrm{A}$ & 1484,0 & 4,2 \\
\hline 12 & 2312,1 a B & 2485,3 a A & 2398,7 & 2,6 \\
\hline 18 & $1933,3 \mathrm{~b} \mathrm{~A}$ & 2004,6 b A & 1968,9 & 3,5 \\
\hline 24 & 472,3 e $\mathrm{A}$ & 496,8 e $\mathrm{A}$ & 484,6 & 6,9 \\
\hline Média & 1402,6 & 1477,3 & & \\
\hline CV $(\%)$ & 3,3 & 4,0 & & \\
\hline
\end{tabular}

Médias seguidas pela mesma letra maiúscula na linha e da mesma letra minúscula na coluna não diferem estatisticamente entre si, pelo teste de Tukey, a $5 \%$ de probabilidade.

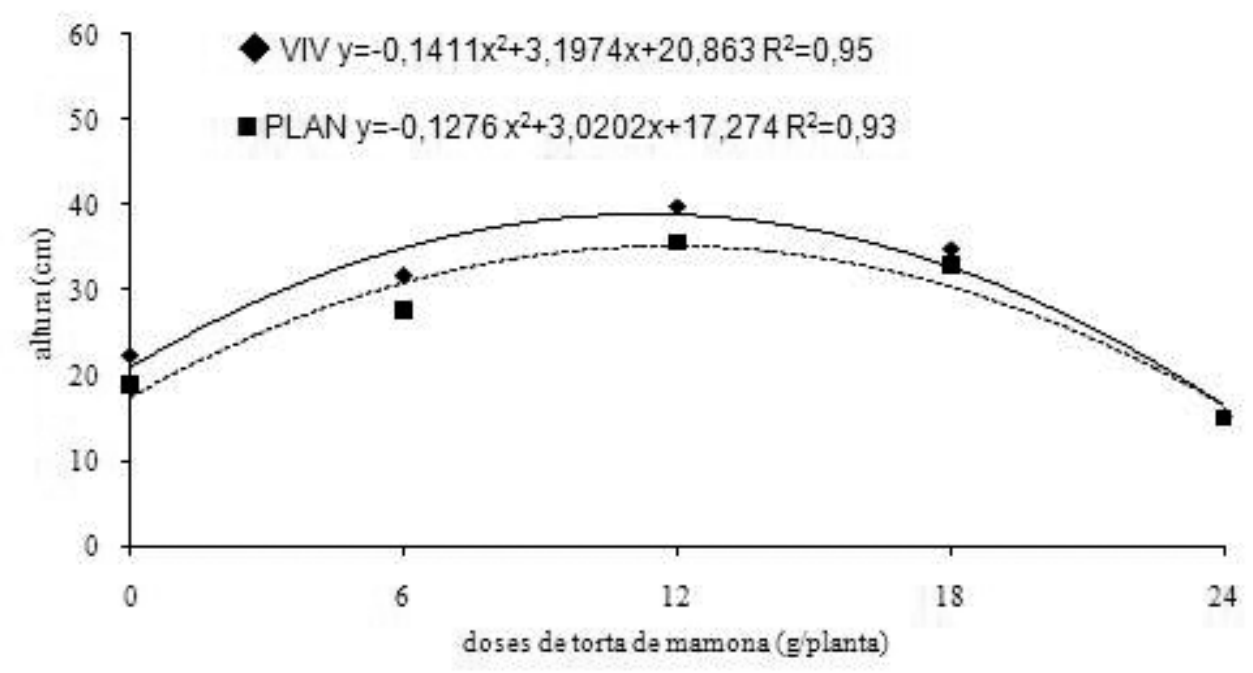

FIGURA 1 - Efeito de doses de torta de mamona adicionadas aos dois substratos (Vivatto Slim Plus ${ }^{\circledR}$ - VIV e Plantmax ${ }^{\mathrm{TM}}$ - PLAN) na altura de mudas micropropagadas de bananeira, cv. Willians, na fase de aclimatação. Assis-SP. 


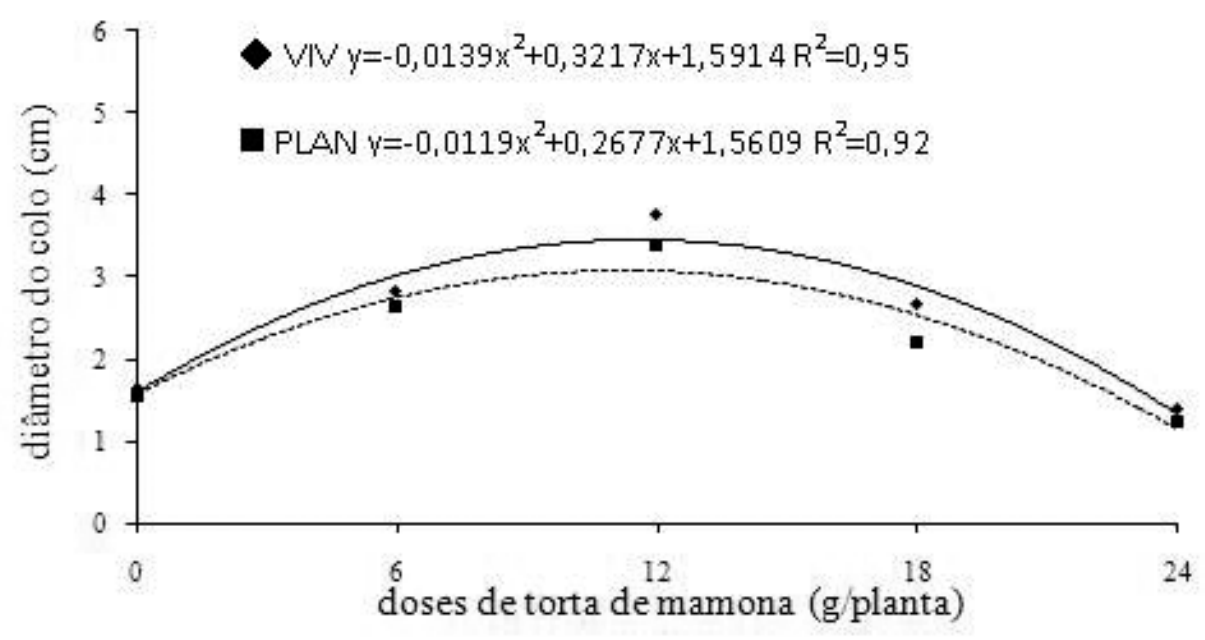

FIGURA 2 - Efeito de doses de torta de mamona adicionadas aos dois substratos (Vivatto Slim Plus ${ }^{\circledR}$ - VIV e Plantmax ${ }^{\mathrm{TM}}$ - PLAN) no diâmetro do colo de mudas micropropagadas de bananeira, cv. Willians, na fase de aclimatação. Assis,-SP.

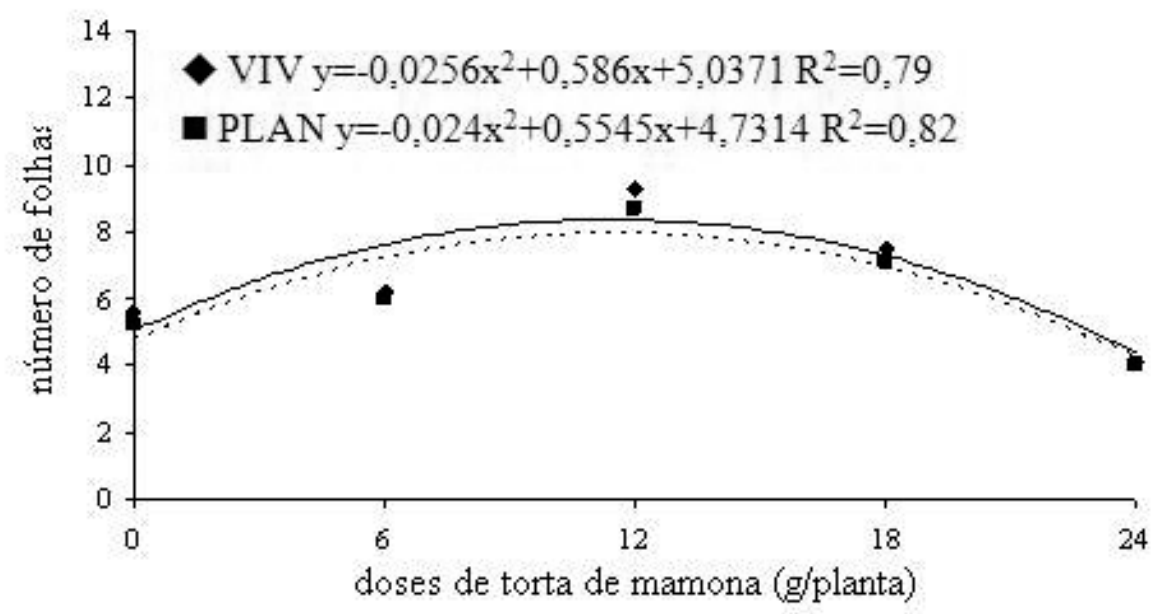

FIGURA 3 - Efeito de doses de torta de mamona adicionadas aos dois substratos (Vivatto Slim Plus ${ }^{\circledR}$ - VIV e Plantmax ${ }^{\mathrm{TM}}$ - PLAN) no número de folhas das mudas micropropagadas de bananeira, cv. Willians, na fase de aclimatação. Assis-SP. 


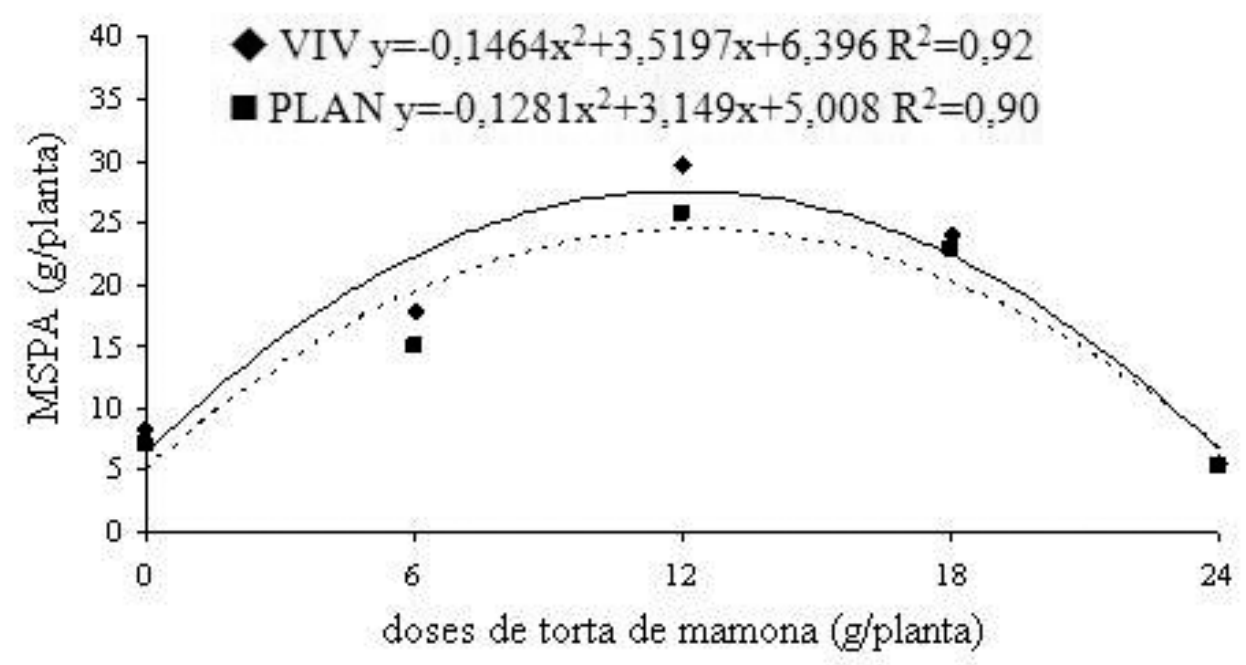

FIGURA 4 - Efeito de doses de torta de mamona adicionadas aos dois substratos (Vivatto Slim Plus ${ }^{\circledR}$ - VIV e Plantmax ${ }^{\mathrm{TM}}$ - PLAN) na massa seca da parte aérea (MSPA) das mudas micropropagadas de bananeira, cv. Willians, na fase de aclimatação. Assis-SP.

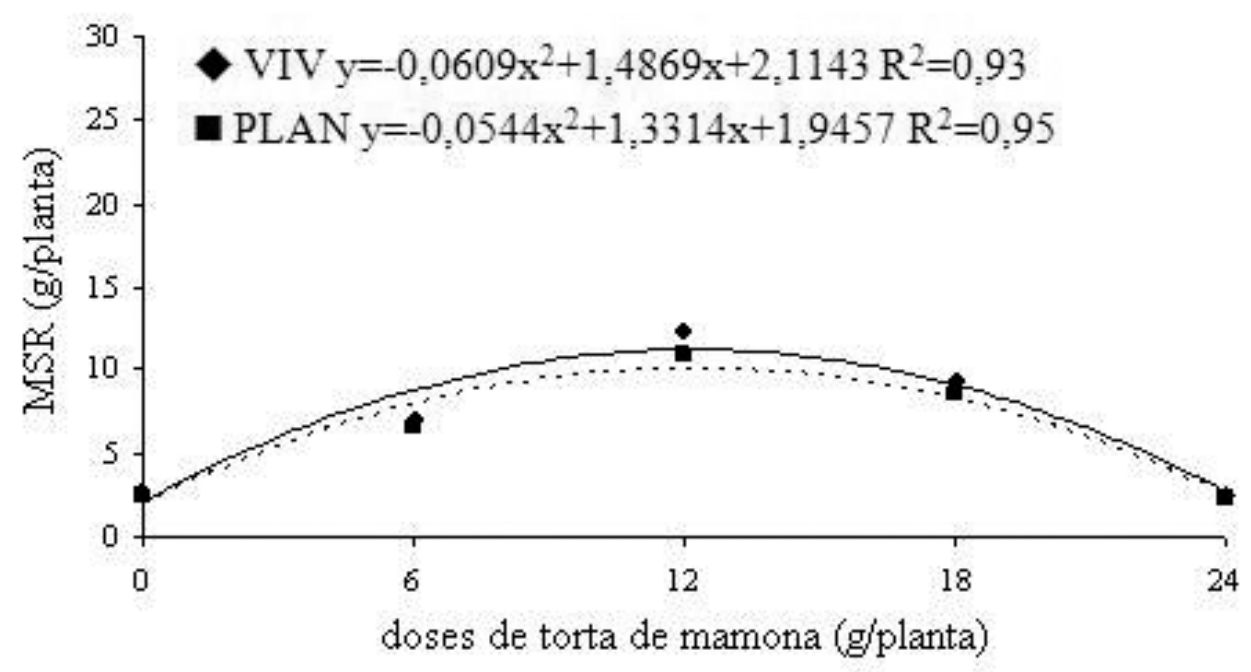

FIGURA 5 - Efeito de doses de torta de mamona adicionadas aos dois substratos (Vivatto Slim Plus ${ }^{\circledR}$ - VIV e Plantmax ${ }^{\mathrm{TM}}$ - PLAN) na massa seca do sistema radicular (MSR) das mudas micropropagadas de bananeira, cv. Willians, na fase de aclimatação. Assis-SP. 


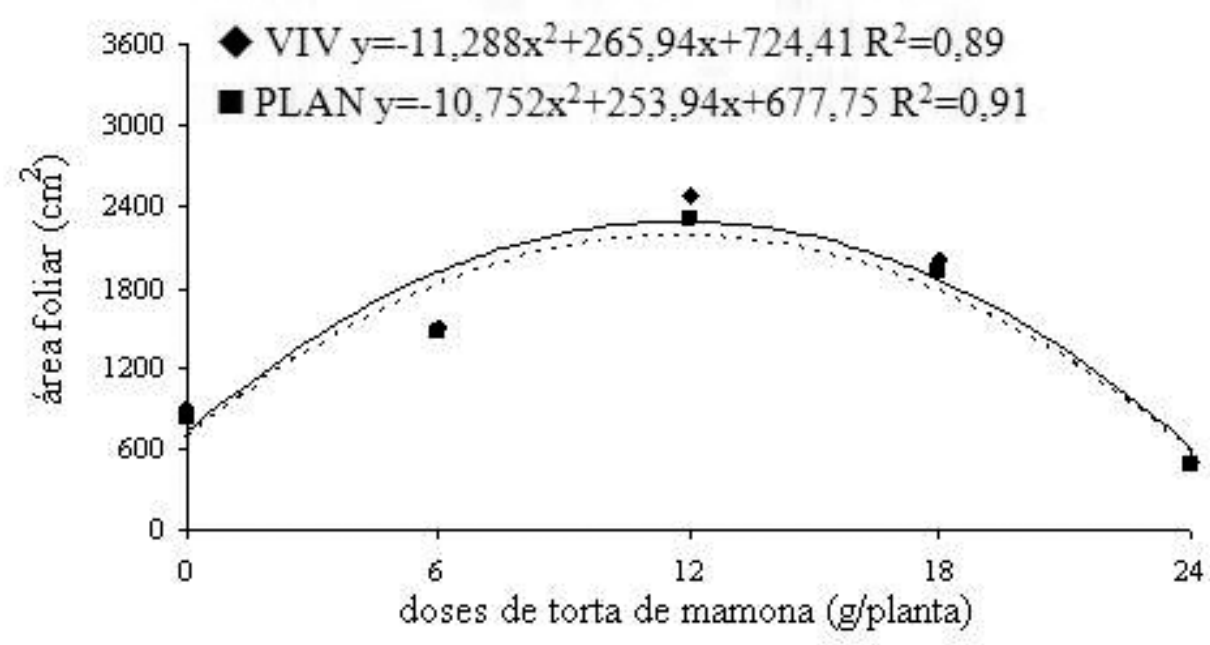

FIGURA 6 - Efeito de doses de torta de mamona adicionadas aos dois substratos (Vivatto Slim Plus ${ }^{\circledR}$ VIV e Plantmax ${ }^{\mathrm{TM}}$ - PLAN) na área foliar (AF) das mudas micropropagadas de bananeira, cv. Willians, na fase de aclimatação. Assis-SP.

\section{CONCLUSÃO}

1- Não são recomendadas doses superiores a 12 g planta $^{-1}$ de torta de mamona como matéria orgânica na aclimatação de mudas de bananeira.

2- O substrato Vivatto Slim Plus ${ }^{\circledR}$ possibilita o melhor desenvolvimento quanto às variáveis avaliadas das mudas na aclimatação de bananeiras micropropagadas.

\section{AGRADECIMENTOS}

Os autores agradecem à Prefeitura Municipal de Assis-SP, na pessoa da Secretária Municipal do Meio Ambiente, Sra. Nilza Ferreira da Silva, pelo apoio material e humano fornecido para a realização deste trabalho.

\section{REFERÊNCIAS}

BASANTA, M. del V.; DOURADO-NETO, D.; GARCIA, A.G. Estimativa do volume máximo de calda para aplicação foliar de produtos químicos na cultura do milho. Scientia Agricola, Piracicaba, v. 57, n. 2, p. 283-288. 2000.

BEUGNON, M.; CHAMPION, J. Étude sur racines du bananier. Fruits, Paris, v.21, n.7, p. 309-327, 1966.
COSTA, F.X.; LIMA, V.L.A.; BELTRÃO, N.E.M.; NUNES JÚNIOR, E.S.; DAMACENO, F.A.V.; GUIMARÃES, M.M.B.; LUCENA, A.M.A.; TRESENA, N.L.; MADEIROS, L.B.; DUTRA, R.C.; SILVA, F.M.O. Modificações ocorridas no ambiente edáfico causadas pela compactação e adição de torta de mamona. In: CONGRESSO BRASILEIRO DE MAMONA, 3., 2008, Salvador, Anais... Campina Grande: Embrapa Algodão, 2008. Disponível em: $<$ http://www.cnpa.embrapa.br/produtos/mamona/ publicacoes/cbm3/ trabalhos/FERTILIDADE\%20 E\%20ADUBACAO/FA\%2004.pdf>. Acesso em: 03 nov. 2009.

DAMASCENO, J.C.A.S.; SANTOS, V.S.; RITZINGER, C.H.S.P.; SANTOS, V.S.; SEVERINO, L.S.; SAMPAIO, A.H.; LEDO, C.A.S.; CALDAS, R.C.C. Uso de farelo de mamona e de nim em mudas de mamoeiro infestadas pelo nematoide das galhas. In: CONGRESSO BRASILEIRO DE MAMONA, 2. 2006, Aracaju. Anais... Campina Grande: Embrapa Algodão, 2006. p. 98-99.

FURLANETO, F.P.B.; MARTINS, A.N.; CAMOLESI, M.R.; ESPERANCINI, M.S.T. Análise econômica de sistemas de produção de banana (Musa sp.), cv. Grande Naine, na região do Médio Paranapanema, Estado de São Paulo. Científica, Jaboticabal, v. 35, n. 2, p. 188-195. 2007. 
GOUZALEZ, R.G.; GOMES, L.A.A.; FRAGA, A.C.; CASTRO NETO, P. Utilização de torta de mamona em substratos para produção de mudas de tomate. In: CONGRESSO DE BIODIESEL,1., 2006. Brasília. Anais... Brasília: Embrapa, 2006. p.140-142.

KIEHL, J.K. Fertilizantes orgânicos. Piracicaba: Ceres, 1985. 492p.

LIMA, R.L.S.; SEVERINO, L.S.; ALBUQUERQUE, R.C.; BELTRÃO, N.E.M.; SAMPAIO, L.R. Casca e torta de mamona avaliados em vasos como fertilizantes orgânicos. Revista Caatinga, Mossoró, v. 21, n. 5 , p. $102-106.2008$ b.

LIMA, R.L.S.; SEVERINO, L.S.; SAMPAIO, L.R.; FREIRE, M.A.O.; SOFIATTI, V.; BELTRÃO, N.E.M. Combinação de casca e torta de mamona como adubo orgânico para a mamoneira. In: CONGRESSO BRASILEIRO DE MAMONA, 3., 2008. Salvador. Anais... Campina Grande: Embrapa Algodão, 2008a. Disponível em: <http://www.cnpa. embrapa.br/produtos/mamona/publicacoes/cbm3/ trabalhos/FERTILIDADE\%20E\%20ADUBACAO/ FA\%2004.pdf $>$. Acesso em: 03 nov. 2009.

LINS, L.C.R.; CONCEIÇÃO, P.J.; FREITAS, J.S.; OLIVEIRA, E.T.; FANCELLI, M.; RITZINGER, C.H.S.P.; COELHO FILHO, M.A.; LEDO, C.A.S. Torta de mamona no desenvolvimento de bananeira cv. Terra e infestação por Cosmopolites sordidus. In: CONGRESSO BRASILEIRO DE FRUTICULTURA, 20., 2008, Vitória. Anais... Jaboticabal: Sociedade Brasileira de Fruticultura, 2008. Disponível em: <http://200.137.78.15/cd_XXCBF/paginas/ Entomologia/20080731_211647.pdf>. Acesso em: 03 nov. 2009.

LOPES, P.S.N.; RAMOS, J.D.; CARVALHO, J.G.; MORAIS, A.R. Efeito da adubação nitrogenada e substratos no crescimento de mudas de maracujazeiro-azedo em tubetes. In: CONGRESSO BRASILEIRO DE FRUTICULTURA, 14., 1996, Curitiba. Anais... Curitiba: Sociedade Brasileira de Fruticultura, 1996. p. 342.

MOREIRA, R.S. Banana: teoria e prática de cultivo. Campinas: Fundação Cargill, 1987. 335 p.

MURASHIGE, T.; SKOOG, F. A revised medium for rapid growth and bioassays with tabacco tissue culture. Physiologia Plantarum, Copenhagen, v.5, n. 4, p. 473-497, 1962.
NASCIMENTO, J.J.V.R.; TAVARES, M.J.V.; SEVERINO, L.S.; SOFIATTI, V. Efeito da torta de mamona sobre o crescimento da mamoneira BRS 149 Nordestina. In: CONGRESSO BRASILEIRO DE MAMONA, 3., 2008, Salvador. Anais... Campina Grande: Embrapa Algodão, 2008. Disponível em: $<$ http://www.cnpa.embrapa.br/produtos/mamona/ publicacoes/cbm3/trabalhos/OLEO\%20E\%20COPRODUTOS/OCP\%2010.pdf $>$. Acesso em: 03 nov. 2009.

NOMURA, E.S.; LIMA, J.D.; RODRIGUES, D.S.; GARCIA, V.A.; FUZITANI, E.J. Influência do substrato e do tipo de fertilizante na aclimatização de mudas de bananeira 'Prata-Anã'. Ciência e Agrotecnologia, Lavras, v. 33, n. 3, p. 773-779. 2009.

RITZINGER, C.H.S.P.; FANCELLI, M. Manejo integrado de nematoides na cultura da bananeira. Revista Brasileira de Fruticultura, Jaboticabal, v. 28, n. 2, p. 331-338. 2006.

SEVERINO, L.S.; COSTA, F.X.; BELTRÃO, N.E.M.; LUCENA, A.M.A.; GUIMARÃES, M.M.B. Mineralização da torta de mamona, esterco bovino e bagaço de cana estimada pela respiração microbiana. Revista de Biologia e Ciências da Terra, Campina Grande, v. 5, n. 1, 2004. Disponível em: <http:// redalyc.uaemex.mx/redalyc/pdf/500/50050105.pdf . Acesso em: 03 nov. 2009.

SEVERINO, L.S.; MORAES, C.R.A.; GONDIM, T.M.S.; CARDOSO, G.D.; SANTOS, J.W. Fatores de conversão do peso de cachos e frutos para peso de sementes de mamona. Campina Grande: Embrapa Algodão, 2005. 15p. (Boletim de Pesquisa e Desenvolvimento, 56).

SILVA, R.P.; PEIXOTO, J.R.; JUNQUEIRA, N.T.V. Influência de diversos substratos no desenvolvimento de mudas de maracujazeiro-azedo (Passiflora edulis Sims f. flavicarpa DEG). Revista Brasileira de Fruticultura, Jaboticabal, v. 23, n. 2, p. 377-381. 2001.

STATISTICALANALYSES SYSTEM. SAS/STAT user's guide. version 6.4. Cary, 2002. 846p.

YAMANISHI, O.K.; FAGUNDES, G.R.; MACHADO FILHO, J.A.; VALONE, G.V. Efeito de diferentes substratos e duas formas de adubação na produção de mudas de mamoeiro. Revista Brasileira de Fruticultura, Jaboticabal, v. 26, n. 2, p. 276-279. 2004. 